\title{
An Atypical Presentation of Multiple Sclerosis
}

\author{
Akshaya A. Shetty, Anannya Mukherji, Manohar Joshi, Sahil Fulara, Nitin Patel \\ D. Y. Patil Hospital \& Research Centre, Nerul, India \\ Email: drakshayashetty@gmail.com
}

Received 17 July 2014; revised 17 August 2014; accepted 16 September 2014

Copyright (C) 2014 by authors and Scientific Research Publishing Inc.

This work is licensed under the Creative Commons Attribution International License (CC BY).

http://creativecommons.org/licenses/by/4.0/

(c) (i) Open Access

\begin{abstract}
Multiple Sclerosis (MS) involves an immune mediated process in which an abnormal response of the body's immune system is directed against the central nervous system (CNS). Multiple sclerosis is a very variable condition and the symptoms depend on which areas of the CNS have been affected. There is no set pattern for MS and everyone with MS has a different set of symptoms, which vary from time to time and can change in severity and duration, even in the same person. Hence diagnosing MS at the earliest is very essential. Therefore we report an unusual case of a 30-yearold female with complaints of headache, vomiting $\&$ hiccups since 2 months followed by weakness of bilateral lower limbs and later upper limbs which eventually were diagnosed as Multiple Sclerosis. We are reporting this case because of the vague clinical presentation of Multiple Sclerosis. Aim: To recognize the symptoms of MS at the earliest and start treatment early.
\end{abstract}

\section{Keywords}

Multiple Sclerosis, Demyelination, Headache

\section{Introduction}

Multiple Sclerosis is a chronic autoimmune disease that targets myelinated axons in the central nervous system. Multiple Sclerosis was believed to be rare in India earlier. However with the advent of the MRI and its penetration into the interiors of India over the last two decades there are increasing number of cases being diagnosed now even in smaller cities. Other reasons are increasing awareness about the disease. Multiple Sclerosis is a significant cause of disability. Headache has been reported as a subtle symptom of onset of Multiple Sclerosis with a variable frequency of $1.6 \%$ to $28.5 \%$, however it remains unclear whether headache is a true symptom of Multiple Sclerosis. It is also unclear if vomiting \& hiccups can be considered as symptoms of MS. Average age of presentation in India is similar to the west with female predominance. 


\section{Case Presentation}

A 30-year-old married female came to us with complaints of vomiting since 2 months. Vomiting was associated with severe headache, more in the occipital region. She also complained of persistent hiccups, had taken some unknown treatment but did not subside. Four days prior to admission, she noticed weakness in both her lower limbs and was unable to walk.

On admission to the hospital, examination of the lower limb showed power of Grade 4/5 bilaterally. Lower limbs were hypotonic and reflexes were absent bilaterally. Plantar response was flexor. There was no sensory involvement and upper limbs were normal.

Day 3 of admission: power in both lower limbs lost completely, Grade 0/5. Reflexes were brisk. Blood investigations (Table 1) were done and were within normal limits. CT brain was normal.

MRI spine report: Mild degenerative disc changes at L4-L5 \& L5-S1 with no spinal cord involvement. CSF examination (Table 2) revealed a tubercular picture hence Anti KOCH’s treatment was started.

Day 5 of admission: Patient gradually developed weakness of bilateral upper limbs which eventually progressed to Grade 0/5. She also developed right inter nuclear ophthalmoplegia. There was no fever or any meningeal signs.

MRI Brain report: A mildly expansile lesion in the medulla which could represent demyelination, infarct or low grade glioma. MR Spectroscopy was advised for confirmation. Patient was then started on intravenous steroids (Inj Methylprednisolone) for demyelinating diease \& antiplatelets for infarction and CSF was repeated and sent for oligloconal bands.

Follow up: Patient started improving and power of all limbs progressed to Grade 3/5. However there were periods of waxing and waning. Later oligoclonal bands in CSF came positive. Hence we started the patient on oral steroids and started tapering the dose. Patient has now recovered with Grade 4/5 power with residual deficit and is following up with us.

Table 1. Blood investigations.

\begin{tabular}{|c|c|c|c|}
\hline Hemoglobin & $12.9 \mathrm{~g} / \mathrm{dl}$ & Total bilirubin & $1.35 \mathrm{mg} / \mathrm{dl}$ \\
\hline Leucocyte count & $9 \times 10^{3} / \mathrm{mUL}$ & Direct bilirubin & $0.3 \mathrm{mg} / \mathrm{dl}$ \\
\hline Platelets & $300 \times 10^{3} / \mathrm{mUL}$ & Indirect bilirubin & $1.0 \mathrm{mg} / \mathrm{dl}$ \\
\hline Sodium & $136 \mathrm{mEq}$ & SGOT & $38.6 \mathrm{IU} / \mathrm{ml}$ \\
\hline Potassium & $4.1 \mathrm{mEq}$ & SGPT & $31.5 \mathrm{IU} / \mathrm{ml}$ \\
\hline Chloride & $101 \mathrm{mEq}$ & Albumin & $3.8 \mathrm{~g} / \mathrm{dl}$ \\
\hline Calcium & $9.0 \mathrm{mmol} / \mathrm{L}$ & Globulin & $2.35 \mathrm{~g} / \mathrm{dl}$ \\
\hline Magnesium & $2.6 \mathrm{mmol} / \mathrm{L}$ & & \\
\hline Creatinine & $0.6 \mathrm{mg} / \mathrm{dl}$ & & \\
\hline
\end{tabular}

Abbreviations: SGOT: Serum glutamic oxaloacetic transaminase; SGPT: Serum glutamic pyruvic transaminase.

Table 2. CSF examination.

\begin{tabular}{cc}
\hline CSF picture & \\
\hline Total cells & $44 / \mathrm{mm}^{3}$ \\
Differential count & $100 \%$ lymphocytes \\
Sugar & $91 \mathrm{mg} / \mathrm{dL}$ \\
Total protein & $128 \mathrm{~g} / \mathrm{L}$ \\
Adenosine deaminase & 19.4 \\
Others & Occasional RBC
\end{tabular}




\section{Discussion}

Multiple Sclerosis was earlier believed to be nonexistent in India [1]. Over the years with the advent of MRI and modification in diagnostic criteria it is now commonly diagnosed in clinical practice.

Onset of MS is varied. It may start with an abrupt disabling symptom like paraplegia or less disabling, insidious, innocuous symptom like tingling over a portion of the trunk. The patient may have minor unilateral symptom but the findings may be more florid and bilateral.

Sometimes a MRI scan done for an unrelated reason may show evidence of MS. Much has been written about the perceived difference in the presentation of MS in India. Earlier studies from India before the MRI era lay stress on the fact that Indian patients had more involvement of optic nerves and spinal cord [2]. In 1985, Singhal found that optico-spinal MS was seen in $71.4 \%$ of their cases. In the same study sensory level occurred in a large number of patients and cerebellar involvement was less frequent.

Jain and Maheshwari analyzed data of 354 cases of MS from nine different centers in India. Optic neuritis $(\mathrm{OPN})$ as the initial presentation was seen in $22.2 \%$ - 58\% of cases [3]. However, more recent studies done in the MRI era from different parts of India have shown a variable visual involvement when compared to west.

Diagnostic Criteria for Multiple Sclerosis: Over the years the diagnostic criteria have evolved to the present revised McDonald's criteria with greater reliance on imaging and laboratory to diagnose early cases. The common theme in all the diagnostic criteria (Schumacher, Poser and now McDonald) has been the requirement to show dissemination in time and space.

The Revised McDonald criteria (2005) are given in the Table 3. These diagnostic criteria are MRI based and simple to follow and should be used to diagnose MS including in India.

Course of Multiple Sclerosis: There are four categories of disease described: relapsing remitting multiple sclerosis (RRMS), secondary progressive multiple sclerosis (SPMS), primary progressive multiple sclerosis (PPMS) and progressive relapsing multiple sclerosis (PRMS). The commonest type of MS in India as in the rest of the world is RRMS [4].

Cerebrospinal Fluid: Oligoclonal bands may be positive in as many as $75 \%-90 \%$ of patients. Positivity for oligoclonal bands (OCB) is variable in different series from India.

Magnetic Resonance Imaging Findings: Magnetic resonance imaging has revolutionized the diagnosis of MS and its differentiation from conditions like acute disseminated encephalomyelitis (ADEM) and acute transverse myelitis (ATM). The MRI criteria which help in the diagnosis of MS are given in Table 4.

Table 3. Revised McDonald criteria (2005).

\begin{tabular}{lll}
\hline Clinical attacks & Objective lesion & Additional requirement \\
\hline 2 or more & 2 or more & None \\
2 or more & 1 & Dissemination in space by MRI or 2 or more MRI lesions consistent with MS plus positive CSF \\
1 & 2 or more & Dissemination in time by MRI or second clinical attack \\
1 & 1 & $\begin{array}{l}\text { Dissemination in space by MRI or } 2 \text { or more MRI lesions consistent with MS } \\
\text { plus positive CSF and dissemination in time by MRI or second clinical attack }\end{array}$ \\
& $\begin{array}{l}\text { Disease progression for } 1 \text { year and } 2 \text { out of } 3 \text { of the following } \\
0\end{array}$ & $\begin{array}{l}\text { a) Positive brain MRI } \\
\text { bo } \quad \text { Positive spinal cord MRI }\end{array}$ \\
\hline
\end{tabular}

Abbreviations: CSF: Cerebrospinal fluid; MRI: Magnetic resonance imaging; MS: Multiple sclerosis.

Table 4. MRI findings.

\begin{tabular}{ll}
\hline & Three out of four of following. \\
MRI evidence of dissemination in space & a) 1 gadolinium enhancing brain or cord lesion \\
& b) 1 or more brain infratentorial or cord lesions \\
MRI evidence of dissemination in time & c) 1 or more juxtacortical lesions \\
& d) 3 or more periventricular lesions \\
& A gadolinium enhancing lesion detected in scan atleast 3 months after \\
& the onset of initial clinical event at a site different from initial event \\
\hline
\end{tabular}




\section{Treatment}

The treatment of patients with MS involves treatment of acute relapses, disease modifying drugs and symptomatic therapy.

Disabling relapses are best treated with IV methyl prednisolone 1 gram for a period of 3 - 5 days [5]. This may be followed by a tapering course of oral steroids. However, this largely depends on the individual experience of the treating neurologist. In case of partial recovery from relapse methylprednisolone pulse can be repeated.

Great symptomatic relief can be provided to the patient by addressing issues like bladder and sexual dysfunction, spasticity, weakness, fatigue, tonic spasms, paroxysmal symptoms, depression and cognitive changes [6].

\section{Conclusion}

We demonstrated a possibility of Multiple Sclerosis presenting with severe headache and vomiting. MS exerts a considerable socioeconomic burden on society by affecting the adult in the prime of their productive life. Therefore timely diagnostic studies and treatment can decrease the residual deficits. CSF for oligoclonal bands have been found in variable proportions in different studies. Hence MRI is the most useful tool in making the diagnosis and should include brain and whole spine.

\section{References}

[1] Singhal, B.S. (1985) Multiple Sclerosis-Indian Experience. Annals of the Academy of Medicine, Singapore, 14, 32-36.

[2] Chopra, J.S., Radhakrishnan, K., Sawhney, B.B., et al. (1980) Multiple Sclerosis in North-West India. Acta Neurologica Scandinavica, 62, 312-321. http://dx.doi.org/10.1111/j.1600-0404.1980.tb03042.x

[3] Jain, S. and Maheshwari, M.C. (1985) Multiple Sclerosis: Indian Experience in the Last Thirty Years. Neuroepidemiology, 4, 96-107. http://dx.doi.org/10.1159/000110220

[4] Gangopadhyay, G., Das, S.K., Sarda, P., et al. (1999) Clinical Profile of Multiple Sclerosis in Bengal. Neurology India, 47, $18-21$.

[5] Tremlett, H.L., Luscombe, D.K. and Wiles, C.M. (1998) Use of Corticosteroids in Multiple Sclerosis by Consultant Neurologists in the United Kingdom. Journal of Neurology, Neurosurgery \& Psychiatry, 65, 362-365. http://dx.doi.org/10.1136/jnnp.65.3.362

[6] Henze, T., Riekmann, P. and Toyka, K.V. (2006) Symptomatic Treatment of Multiple Sclerosis-Multiple Sclerosis Therapy Consensus Group (MSTCG) of the German Multiple Sclerosis Society. European Neurology, 56, 78-105. http://dx.doi.org/10.1159/000095699 
Scientific Research Publishing (SCIRP) is one of the largest Open Access journal publishers. It is currently publishing more than 200 open access, online, peer-reviewed journals covering a wide range of academic disciplines. SCIRP serves the worldwide academic communities and contributes to the progress and application of science with its publication.

Other selected journals from SCIRP are listed as below. Submit your manuscript to us via either submit@scirp.org or Online Submission Portal.
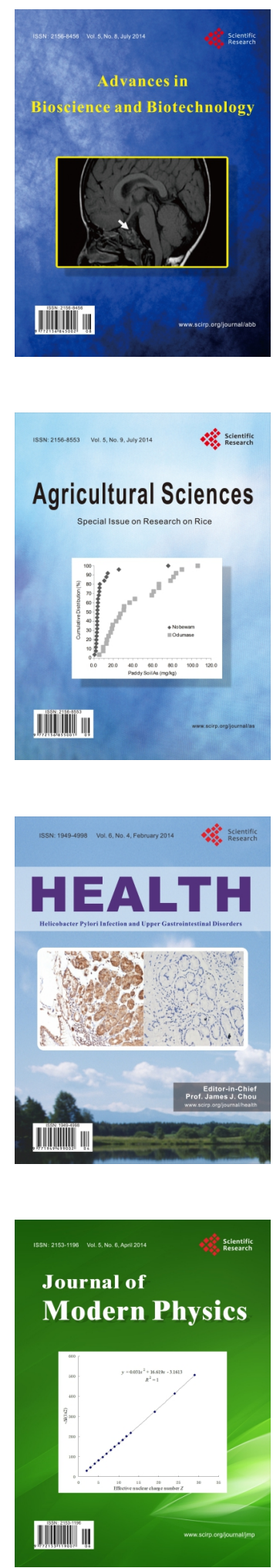
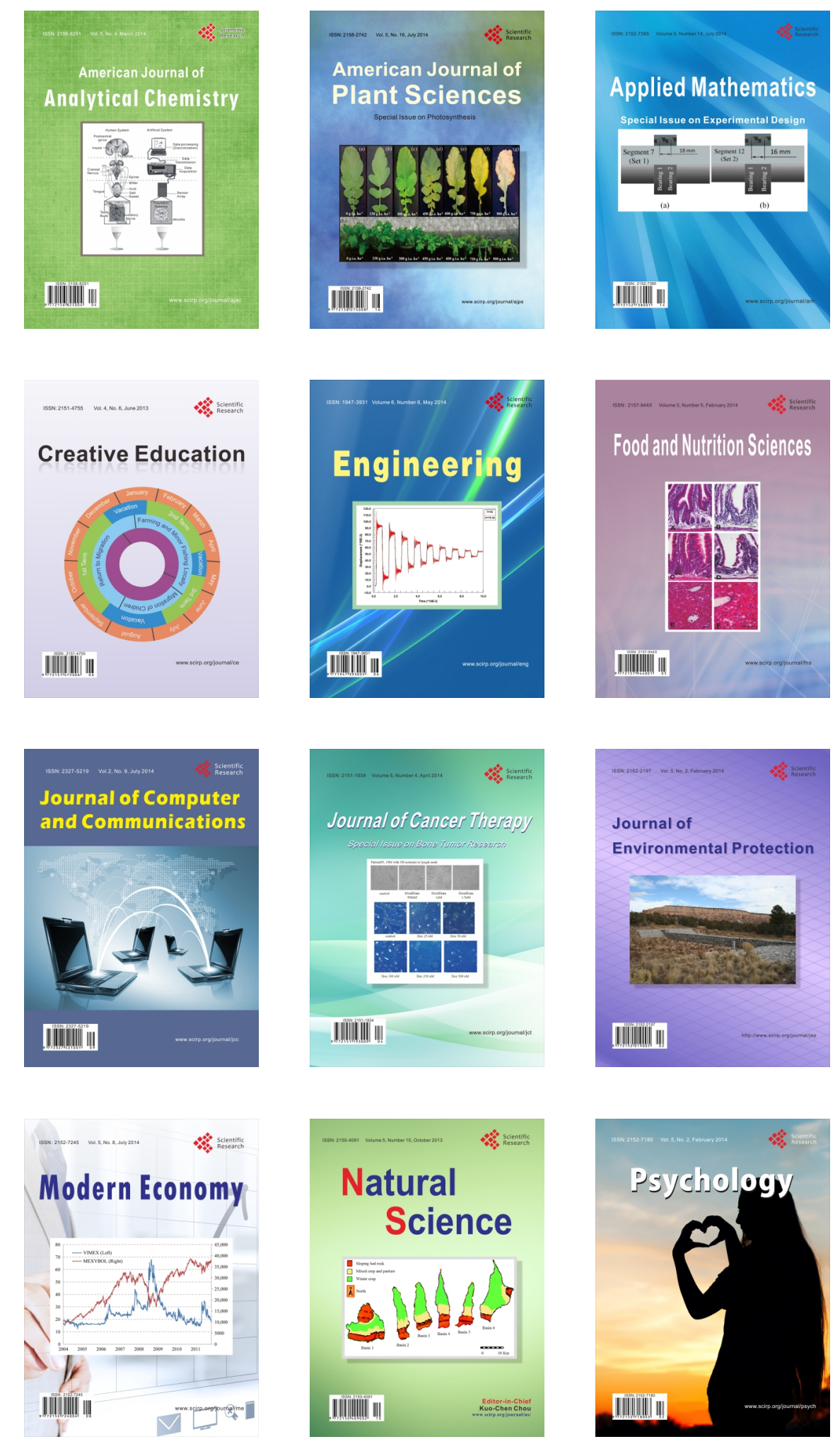